\title{
Automation of crop production in the Siberian region with the development of precision farming technologies
}

\author{
Boris Dokin ${ }^{1, *}$ and Anna Aletdinova ${ }^{2}$ \\ ${ }^{1}$ Siberian Research Institute of Mechanization and Electrification of Agriculture, Krasnoobsk \\ settlement, 630501, Russia \\ ${ }^{2}$ Novosibirsk State Technical University, ERP Systems Department, 630073 Novosibirsk, Russia
}

\begin{abstract}
The development of precision farming technologies in the Siberian region of Russia has a long history. Already in the 80s, the first design solutions appeared, their authors received patents and certificates. But only in the last ten years, with the development of information and communication technologies, with the advent of GPS and Global Navigation Satellite Systems (GLONASS), the production of aggregates for precision farming technologies has expanded. The authors give examples of developments of the Siberian Institute of Mechanization and Electrification of Agriculture, analyze the current state of development of automation of crop production in the Siberian region. By the end of 2020, there are 65 mobile applications to support precision farming technologies. The authors conducted a comparative analysis of them with their foreign counterparts; based on the assessments of Russian crop specialists, the most popular ones were identified.
\end{abstract}

\section{Introduction}

Crop production is one of the main branches of agriculture in Russia. Automation of crop production allows you to effectively and quickly manage the industry. El H. Bilali, O. I. Khairullina note that in 2018, the Lipetsk Region (812 organizations), the Orel Region (110 organizations) and the Samara Region (94 organizations) were among the leaders in the introduction of precision farming technologies in Russia [1].

Precision farming technologies are the management of crop production using information and communication, intelligent technologies. Precision farming technologies include the use of Internet of Things (IoT) devices and sensors to manage agriculture by observing, measuring, responding to, and monitoring inter - and intra-field crop variability [2]. The technologies of precision agriculture include the use of geographic information systems (GIS), automation and robotization of production [3, 4, 5].

The authors set the following research tasks: analysis of patents and author's certificates on crop automation at the Siberian Institute of Mechanization and Electrification of

\footnotetext{
* Corresponding author: aletdinova@corp.nstu.ru
} 
Agriculture; analysis of information support for precision farming technologies, in particular mobile applications.

\section{Related work and methods}

For the introduction of precision farming technologies, there are not enough developments and design solutions of scientists, we need common economic, technological, social and even psychological conditions, most of which can not be created by a single farmer.

\subsection{Related work}

In 1980, the Siberian Institute of Mechanization and Electrification, together with colleagues from the Design Bureau of the Siberian Branch of the All-Russian Academy of Agriculture, received an author's certificate for the "Device for automatically regulating the loading of a combine harvester" [6]. In 1982, employees of the Siberian Institute of Mechanization and Electrification of Agriculture received author's certificates for the "Automatic speed controller of the reel of the combine harvester" and for the "System of automatic regulation and control of the technological process of the combine harvester" [7]. In 1985, they proposed an improved version of this system [8]. Their production was mastered by the Novosibirsk plant "Ekran". All combines of the Krasnoyarsk plant were equipped with the control and measuring systems of the SKI-10TS, the SKI-10TSRcombines of the Niva plant, and the BICH unit-combines of the Rostselmash plant "Don$1200 "$ and "Don-1500".

In Russia, at the exhibition "Day of the Don Field" on August 19, 2020, the Rostselmash plant presented an unmanned combine harvester-TORUM 785, which is equipped with a number of smart systems. The RSM Router system selects the most efficient route for vehicles in the field and provides information about the unloading location. RSM Optima is designed to help you choose the most optimal settings for your harvester, depending on the current conditions. The RSM Level Control system displays the level of grain filling. The RSM Yield Mapping system supports the measurement of threshing at each point of the field and a map of yield and humidity. The RSM AutoDriver and RSM Explorer Plus auto-driving systems automatically control the path of the harvester, they lead it parallel to the previous pass, providing also turns and control of the harvester. The RSM Explorer system uses machine vision, which provides a stop in front of an obstacle. In the future, one operator will be able to manage a group of harvesters.

As for the driving of technical means, these works also began at the Siberian Institute of Mechanization and Electrification. In 1980, the scientists of the institute received two author's certificates: "A method for automatically directing the movement of mobile units along an orienting current-carrying wire" and "A device for automatic group driving of tractor units" [9, 10]. In 1981, they received two more author's certificates: "A method of orientation of self-propelled machines in an alternating field of a current-carrying circuit" and "An induction device for group driving of tractor units" [11, 12], in 1982 - "A device for group driving of tractor units" [13], in 1986 - "A system of double driving of machinetractor units", "A method of driving machine-tractor units along horizontal slopes" and "An induction system of double driving" [14-16], in 1988, another - "The method of double driving of machine-tractor units on horizontal slopes" [17]. Unfortunately, these developments were not used at that time in Russian agricultural production.

These issues were resolved dramatically with the advent of GPS and GLONASS systems. Now they are widely used in agriculture. In the organization "Novomayskoye" of the Krasnozersky district of the Novosibirsk region, a John-Deere tractor with a sowing complex sows 200-250 hectares of grain per day, and a K-744R3 tractor with SZP seeders- 
3.6 for 10 hours 50 hectares. Automation of crop production has provided the emergence of precision farming technologies. Based on the yield map of the field plots obtained after harvesting by the combine harvester, and the map of the soil survey, mineral fertilizers are applied by aggregates in the right place and in a certain amount, this can also be said about herbicides, pesticides and fungicides.

Currently, the automation of technological processes is closely related to the robotization of crop production, the use of the Internet of Things and the creation of geographical information systems. There is a demand for digital ecosystems to enable cross-industry and machine-to-machine interaction. Here we can cite as an example the project "Digital Agriculture" of the Ministry of Agriculture of Russia, which will create a digital ecosystem for managing production, supply and sales; obtaining loans, subsidies, insurance, and hedging; professional development and obtaining expert advice, recommendations; use of electronic trading platforms and analytics; integration into the Internet space. The information technology market offers consumers more and more diverse software every year. Mobile applications for the automation of crop production in Russia have also appeared.

\subsection{Methods}

For the study, the authors analyzed the patents and author's certificates of the Siberian Institute of Mechanization and Electrification of Agriculture in order to select documents dedicated to the automation of crop production.

The authors selected mobile applications to support precision farming technologies for Android iOS operating systems, as they are the most popular. Mobile app categories are defined by app stores. To classify them, we used the summary and grouping method.

The respondents were specialists, plant workers, who have experience in using mobile applications in the amount of 24 people (the maximum score is 24 , since the respondents could choose any number of mobile applications).

\section{Results and discussion}

The authors analyzed the available mobile applications in Russia to support precision farming technologies and grouped them by application area: for monitoring and changing the technological parameters of crop production; crop production planning, etc. At the end of 2020, the total number of applications was about 65 , of which $95.3 \%$ of the applications are in Russian, most of them are free. All have user ratings.

The "Technical Means Management" group contains only applications for navigating technical means. Reviews of them from users are positive, the average quality rating is 4.7 out of 5 points. Examples of mobile applications: Drone Remote Control, Field Bee GPS, Field Navigator, Agrilus-NAVI GPS/GNSS, Tractor Guide, Cropio Telematics, AgroPilot, etc.

The second group "Control and change of technological parameters of crop production" contains mobile applications from the categories Navigation, Business and Productivity. This includes applications for measuring and videotaping land plots, supporting a system for measuring soil moisture and irrigation management, agro-calculators, diaries for monitoring fields, and maintaining farm statistics. User satisfaction ratings for these apps range from 2.8 to 4.6. Their examples: Agronote farming expenses, Agrocalculator, GPS.Fields, GPS.Field area measurement, Hydrawise, Agronomist Assistant 1C: ERP APK2, Cropio, Agronomist, etc.

The third group contains mobile apps from the Business category. This includes applications for planning agricultural production, placing crops in the fields using the GIS 
function, if necessary. User satisfaction ratings for these apps are low (less than 3 out of 5). Examples of such mobile applications: Farm Management Pro, fieldmargin: simple farm management, Farming Solution, etc.

The largest group is the last one, where we have included applications for making management decisions. It includes electronic reference books and catalogs, platforms for interaction between consultants, specialists and plant workers, methodological recommendations for regulation, configuration, troubleshooting and selection of equipment. This group combined mobile apps from the Education, Business, and Reference categories. Users rated the satisfaction with the auxiliary applications very high, from 4.1 to 4.8. Their examples are: AGRIO-Smart Agriculture, Agriculture (Kirlanik LLC), Agrobase-weed, Insect, Organic Farming Hormones, Direct.Farm, etc.

The authors asked the respondents (description in Methods) to choose the most popular applications from these applications. We compared the results obtained with a sample of mobile applications for crop automation "Top 21 List of Agriculture Mobile Apps for 2020" [18].

The most popular among Russian crop workers (based on expert assessments of respondents) were: navigation, agro-calculators, nitrogen content management, an auxiliary platform for precision farming technologies, drawing up technological maps and reference books (Table 1). You can see significant differences in the preferences of Russian and foreign crop workers.

Table 1. The popular group of mobile applications to support precision farming technologies.

\begin{tabular}{|c|c|c|}
\hline $\begin{array}{c}\text { Field of } \\
\text { application }\end{array}$ & $\begin{array}{l}\text { Groups of mobile applications popular in the world } \\
\text { [18] }\end{array}$ & $\begin{array}{l}\text { Groups of mobile } \\
\text { apps that are } \\
\text { popular in Russia }\end{array}$ \\
\hline $\begin{array}{l}\text { Management } \\
\text { of technical } \\
\text { means }\end{array}$ & $\begin{array}{l}\text { Logistics of the machine and tractor fleet } \\
\text { (GrainTruckPlus) } \\
\text { Drone Flight Control (AgVault 2.0 Mobile) }\end{array}$ & Navigation \\
\hline $\begin{array}{l}\text { Control and } \\
\text { change of } \\
\text { technological } \\
\text { parameters of } \\
\text { crop } \\
\text { production }\end{array}$ & $\begin{array}{c}\text { Nitrogen Uptake Tester for plants (Yara ImageIT) } \\
\text { Field statistics (FarmLogs) } \\
\text { Recording of chemical treatment areas of fields (GPS } \\
\text { Area Measure) } \\
\text { Vegetation density assessment (Canopen) }\end{array}$ & $\begin{array}{l}\text { Nitrogen uptake } \\
\text { tester for plants } \\
\text { Agro-calculator } \\
\text { Auxiliary platform } \\
\text { for supporting } \\
\text { precision farming } \\
\text { technologies }\end{array}$ \\
\hline $\begin{array}{l}\text { Crop } \\
\text { production } \\
\text { planning }\end{array}$ & $\begin{array}{c}\text { Nutrient Calculator for crop yield planning (Nutrient } \\
\text { ROI Calculator 2.0.) }\end{array}$ & $\begin{array}{l}\text { Preparation of } \\
\text { technological } \\
\text { maps }\end{array}$ \\
\hline Auxiliary & $\begin{array}{c}\text { Reference books (ID Weeds, SoilWeb) } \\
\text { Sharing field data for farmers to make collective decisions } \\
\text { (Cirrus Premium Upgrade) } \\
\text { Detailed weather forecast and information support for your } \\
\text { own weather stations (Wunderground) } \\
\text { Pocket Rain Gauge ( Pocket Rain Gauge) } \\
\text { Chemical mixing system. Guidelines (Tank Mix } \\
\text { Calculator, Mixmate) } \\
\text { Platform for interaction between consultants, specialists } \\
\text { and farmers (AgriSync) } \\
\text { Seed Sales Analytics (AgSentry) } \\
\text { Solutions) } \\
\text { Control of quotas for harvesting, reporting (mAgri } \\
\text { Products for farmers (Ag Guardian) } \\
\text { Evaluating the effectiveness of management decisions } \\
\text { (Ohio State PLOTS) } \\
\text { Weekly crop forecast by State (Descartes Crops) }\end{array}$ & References \\
\hline
\end{tabular}


This is due to the level of information support for crop automation, geography, agriculture system, technology development, the level of digitalization of the economy and education, mentality, etc.

At this stage of automation of crop production in Russia, mobile applications are most often duplicated by other software. Currently, in the Siberian region, automatic driving of sowing complexes, sprayers, combine harvesters and other machine-tractor units can increase the productivity of machine operators by $10-15 \%$, and automation of regulation and control of the technological process of the combine harvester reduces crop losses by $10-12 \%$.

\section{Conclusion}

The first attempts to develop automated units at the Siberian Institute of Mechanization and Electrification of Agriculture failed, they were not introduced into production. But in modern conditions, with the development of information and communication technologies, precision farming technologies, and new design solutions, this has become possible. In the Siberian region, only $1 \%$ of arable land is cultivated using precision farming technologies. GPS and GLONASS systems are used for this purpose.

The authors have grouped mobile applications for supporting precision farming technologies by application area: management of technical means; control and change of technological parameters of crop production; planning of crop production; auxiliary. Users gave fairly high ratings to applications for navigation and management decision - making (agro-calculators, platforms for interaction between consultants, specialists and farmers, reference books, drawing up technological maps, etc.). You can see the difference in the results of the study with the "Top 21 List of Agriculture Mobile Apps for 2020", which we explained by the different levels of support for crop automation, the farming system, the socio-geographical and economic features of production. The emergence of precision farming technologies is based on the use of information and communication technologies and requires further development of their software.

\section{References}

1. El H. Bilali, O.I. Khairullina ICT \& Precision agriculture (Perm, 2018)

2. D.D. Dasig Internet of Things and Analytics for Agriculture 2 (2020)

3. I. Bhakta, S. Phadikar, K. Majumder Journal of the Science of Food and Agriculture 99, 11 (2019)

4. X.T. Yan, A. Bianco, C. Niu, R. Palazzetti, G. Henry, Y. Li, R. Scott Reinventing Mechatronics (Springer, Cham, 2020)

5. K. Mashkov, V. Rubtsov, I. Rubtsov MATEC Web of Conf. 224 (2018)

6. G.P. Zhdanov, A.V. Kuznetsov, G.E. Chepurin Bulletin 25745417 SSSR MKI A 01 D 41\12. (1980) (In Russian)

7. G.P. Zhdanov, G.E. Chepurin Bulletin 6904554 SSSR, MKI A 01 D 41/12, A 01 D 69/00 (1980) (In Russian)

8. V.S. Kozachenko, G.P. Zhdanov, G.E. Chepurin Bulletin 35959682 SSSR, MKI A 01 F $41 \backslash 12$ (1982) (In Russian)

9. V.S. Kozachenko, S.V. Sakhonchik, G.E. Chepurin Bulletin $321175386 S S S R$, MKI A 01 D 41/12 (1985) (In Russian)

10. A.T. Kalyuzhnyi Bulletin 28751343 SU, MPK3 A 01 V69/04 (1980) (In Russian) 
11. A.T. Kalyuzhnyi, V.A. Zmanovskii, I.I. Korolev, V.V. Lazovskii Bulletin 28751344 SU, MPK3 A 01 V69/04 (1980) (In Russian)

12. A.T. Kalyuzhnyi, V.V. Lazovskii Bulletin 9810112 SU, MPK3 A 01 V69/04 (1981) (In Russian)

13. A.T. Kalyuzhnyi, M.V. Emel'yanov Bulletin 20829001 SU, MPK3 A 01 V69/04 (1981) (In Russian)

14. A.T. Kalyuzhnyi Bulletin 201233828 SU, MPK3 A 01 V69/04 (1986) (In Russian)

15. A.T. Kalyuzhnyi, V.V. Lazovskii, V.A. Dneprovskii Bulletin 241240372 SU (1986) (In Russian)

16. A.T. Kalyuzhnyi Bulletin 281246911 SU, MPK4 A 01 V69/04 (1986) (In Russian)

17. A.T. Kalyuzhnyi, V.S. Abushenko, M.V. Emel'yanov, I.I. Korolev Bulletin 11 1382417 SU, MPK4 A 01 V69/04 (1988) (In Russian)

18. Top 21 List of Agriculture Mobile Apps for 2020. Url: https://www.agrotechnomarket.com/2017/09/list-of-agriculture-mobile-apps.html 